\title{
Impact of future climate change on malaria in West Africa
}

\author{
Ibrahima Diouf ${ }^{1,2}$ - Abiodun M. Adeola $a^{3,4,5}$. Gbenga J. Abiodun ${ }^{6} \cdot$ Christopher Lennard $^{7}$. Joyce M. Shirinde ${ }^{8,9}$. \\ Pascal Yaka ${ }^{10}$. Jacques-André Ndione ${ }^{11}$. Emiola O. Gbobaniyi ${ }^{12}$
}

Received: 30 December 2020 / Accepted: 1 October 2021 / Published online: 20 October 2021

(C) The Author(s) 2021

\begin{abstract}
Understanding the regional impact of future climate change is one of the major global challenges of this century. This study investigated possible effects of climate change on malaria in West Africa in the near future (2006-2035) and the far future (2036-2065) under two representative concentration pathway (RCP) scenarios (RCP4.5 and RCP8.5), compared to an observed evaluation period (1981-2010). Projected rainfall and temperature were obtained from the coordinated regional downscaling experiment (CORDEX) simulations of the Rossby Centre Regional Atmospheric regional climate model (RCA4). The malaria model used is the Liverpool malaria model (LMM), a dynamical malaria model driven by daily time series of rainfall and temperature obtained from the CORDEX data. Our results highlight the unimodal shape of the malaria prevalence distribution, and the seasonal malaria transmission contrast is closely linked to the latitudinal variation of the rainfall. Projections showed that the mean annual malaria prevalence would decrease in both climatological periods under both RCPs but with a larger magnitude of decreasing under the RCP8.5. We found that the mean malaria prevalence for the reference period is greater than the projected prevalence for 6 of the 8 downscaled GCMs. The study enhances understanding of how malaria is impacted under RCP4.5 and RCP8.5 emission scenarios. These results indicate that the southern area of West Africa is at most risk of epidemics, and the malaria control programs need extra effort and help to make the best use of available resources by stakeholders.
\end{abstract}

\section{Introduction}

Several vector-borne diseases such as malaria are very sensitive to climate and weather conditions (Tompkins and Ermert 2013, Abiodun et al. 2016, Abiodun et al. 2017;

Abiodun M. Adeola

abiodun.adeola@weathersa.co.za

1 Climate Prediction Center, National Weather Services, National Oceanic and Atmospheric Administration, 5830 University Research Court, College Park, MD 20740, USA

2 Laboratoire de Physique de L'Atmosphère Et de L'Océan-Siméon Fongang, Ecole Supérieure Polytechnique de L, UniversitéCheikh Anta Diop (UCAD), Dakar-Fann, BP 5085, 10700 Dakar, Senegal

3 South African Weather Service, Private Bag X097, Pretoria 0001, South Africa

4 Institute for Sustainable Malaria Control, School of Health Systems and Public Health, University of Pretoria, Pretoria 0002, South Africa

5 Centre for Environmental Studies, Department of Geography, Geoinformatics and Meteorology, University of Pretoria, Private Bag X20, Hatfield 0028, South Africa
Abiodun et al. 2018). When unusual conditions prevail, for example, during heavy rainfall periods, mosquito populations can multiply and trigger epidemics. In desert regions and highlands bordering malaria epidemic areas, transmission is unstable, and the human population is not immune

6 Mathematics Department, Southern Methodist University, Dallas, TX, USA

7 Climate System Analysis Group Department, Environmental and Geographical Science, University of Cape Town, Private Bag X3, Rondebosch 701, South Africa

8 Air Quality, Modeling and Environmental Health Group, Council for Scientific and Industrial Research, Pretoria, South Africa

9 School of Health Systems and Public Health, University of Pretoria, Pretoria 0002, South Africa

10 Agence Nationale de la Météorologie, Ouagadougou, Burkina Faso

11 Centre de Suivi Ecologique, Fann Résidence, BP 15532, 10700 Dakar, Senegal

12 Swedish Meteorological and Hydrological Institute, Norrköping, Sweden 
(Pascual et al. 2006; Menne and Bertollini 2000; Wandiga et al. 2010; Alonso et al. 2011). Climate variability and change have been linked with malaria transmission in most West African countries: Benin, Burkina Faso, Cabo Verde, Côte D'Ivoire, Gambia, Ghana, Guinea, Guinea-Bissau, Liberia, Mali, Mauritania, Niger, Nigeria, Senegal, Sierra Leone, and Togo (Ayanlade et al. 2020, Diouf et al. 2020; Makinde et al. 2021). For example, severe epidemics can occur when atmospheric conditions (precipitation and temperature) become favorable for transmission. Malaria risk fluctuations have been associated over time with changes in rainfall in relation to El Niño (Poveda et al. 2001; Gagnon et al. 2002; Kovats et al. 2003; Mabaso et al. 2007; Hanf et al. 2011).

In the climate-health issue, many studies have investigated the influence of climatic parameters on the epidemiology of malaria (Gupta and Hill 1998). Climate change can modulate malaria transmission through increased temperature (Freeman et al. 1996). High temperatures also reduce the duration of the parasite's reproductive cycle inside the mosquito (Tompkins and Ermert 2013). Disturbances in the intensity and frequency of the precipitation system may modulate the development of the mosquito population (Abiodun et al. 2016, 2018).

Rainfall is another key factor determining the existence of the Anopheles species, their abundance, and the duration of the malaria transmission season (Lindsay and Birley 1996; Besancenot et al. 2004; Abiodun et al. 2016). West Africa experienced the worst floods during the last 50 years which caused several damages to human settlement (Magadza 2000; Armah et al. 2010; Nka et al. 2015). Contrarily, since the 1970s in the Sahel and Senegal, rainfall has decreased by almost $30 \%$ with persistent droughts in 1972 to 1983 and 1991 to 1992 (Hulme 1992; Newby et al. 2015). According to Mouchet et al. (1996), paradoxically, drought in the Sahel has considerably reduced the distribution and abundance of mosquitoes, without being associated with a drastic reduction of malaria. A concurrent reduction in the effectiveness of malaria treatment drugs justifies this observation (Newby et al. 2015).

The potential impact of $1.5{ }^{\circ} \mathrm{C}$ and $2{ }^{\circ} \mathrm{C}$ global warming on consecutive dry and wet days has recently been investigated over the region (Klutse et al. 2018). As shown in other studies in Senegal at local and national scales (Diouf et al. 2013, 2017), Benin (Ayanlade et al. 2020), Nigeria (Makinde et al. 2021), Tourre et al. 2017 and over West Africa (Diouf et al. 2020). The risk of malaria transmission is primarily associated with climate parameters, particularly rainfall and temperature, with a 2-month lag observed between the rainfall peak in August and the peak in malaria cases in October.

In general, Diouf et al. 2020 showed particular interest in the predictability of high malaria occurrences in Senegal and West Africa. Many other studies have been carried out on the vector-borne disease in many areas in West Africa as part of projects targeted in the framework of climate change and health (AMCEN 2011; Caminade et al. 2011; Caminade et al. 2014; UNEP 2013). For instance, Gadiaga et al. (2011) studied conditions of malaria transmission in Dakar, Senegal, from 2007 to 2010 through an extensive entomological survey that was conducted in 45 zones. These authors found strong spatial and temporal heterogeneity of Anopheles gambiae s.l. larval density, HBR (human biting rate), and malaria transmission in Dakar. The work of Githeko and Ndegwa (2001) focused on East Africa, showing that the warm phase of ENSO (e.g., El Niño) led to floods and malaria outbreaks in Kenya. Large-scale modes of climate variability, including the El Niño southern oscillation (ENSO), have been shown to significantly impact mosquito-borne diseases in the tropics, including malaria (Kreppel et al. 2019).

Yamana and Eltahir (2013) assessed the effect of climate change on malaria transmission in West Africa using Hydrology, Entomology, and Malaria Transmission Simulator (HYDREMATS) with climate projections from general circulation models. Their findings highlighted the importance of rainfall in shaping the impact of climate change on malaria transmission in future climates. However, the climate data obtained from global climate models (GCMs) is usually at a fairly coarse resolution and often of limited application in regional studies. In comparison, regional climate models (RCMs) which focus over a smaller area of interest can provide climate data at higher resolutions (e.g., 25-50 km). The present study utilizes the Coordinated Regional Climate Downscaling Experiment (CORDEX) simulations dataset in the Liverpool malaria model (LMM) to project impacts of climate change on malaria prevalence (e.g., the influence on malaria zone) in West Africa in the future. The study enhances our understanding on how these regional climates are impacted under RCP4.5 and RCP8.5 emission scenarios, as well as the timings of the changes. Hence, the primary aim of the study is to evaluate the ability of CORDEX simulations to reproduce historical malaria features and investigate projected changes across the West African domain.

The main reason to focus our study over West Africa is that according to the WHO in its report 2018, in 2016, about $90 \%$ of the 200 million infections and $91 \%$ of the 455,000 annual deaths linked to malaria disease were found in subSaharan Africa including West Africa. This fact shows that malaria is endemic in West Africa. This disease also has a high impact on the economy because, according to the WHO, malaria slows economic growth by causing heavy expenditure of around $25 \%$ on household income and constitutes $40 \%$ of public health expenditure. West African countries are not yet ready to face the consequences of climate 
change. They lack strong evidence of the links between health and climate. In most West African countries, the capacities needed to understand climate and environmental information are not yet up to par. This problem prevents having concrete results for decision-making and resource management. This work is part of a contribution to research on the impact of climate change which is a real problem influencing the transmission of malaria in West Africa.

\section{Materials and methods}

\subsection{Study area}

This study is focused on the western region of Africa. The region according to classification by the African Union consists of 15 member countries that include Benin, Burkina Faso, Cabo Verde, Côte D'Ivoire, Gambia, Ghana, Guinea, Guinea-Bissau, Liberia, Mali, Mauritania, Niger, Nigeria, Senegal, Sierra Leone, and Togo having a total of about 410 million population (UNWPP 2019) (see Fig. 1). About 394 million people living in the countries of West Africa are at high risk of malaria except for Cabo Verde which had zero indigenous cases since February 2018 (WHO, malaria report 2020). Malaria is transmitted in the region all year round and largely due to $P$. falciparum, with strong seasonality. The region is reported to have recorded about 112 million malaria cases and about 196000 associated deaths. Given a large population, Nigeria (54\%), Burkina Faso (7\%), Côte d'Ivoire (7\%), Niger (7\%), and Mali (6\%) account for about $81 \%$ of the reported malaria cases (WHO, malaria report
2020). The region has distinct two seasons known as the wet and dry seasons resulting from the interaction of two migrating air masses: the hot, dry tropical continental air mass and the moisture-laden, tropical maritime or equatorial air mass. The prevailing climatic conditions such as high temperatures and rainfall that characterize the region all year round create an ambient environment including vegetation that favors the breeding and survival of the malaria vectors.

\subsection{Climate data and methods}

In this study, we have used climate data from the RCA4 regional climate model forced by ERA-Interim reanalysis (Dee et al. 2011) and eight (8) global circulation models. The RCA4 regional climate model (Jones et al. 2011a, b; Dieterich et al. 2013) used in this study was developed at the Swedish Meteorological and Hydrological Institute and has provided nearly 120 simulations in the CORDEX project (Coordinated Regional Climate Downscaling Experiment). The model considers the physical, chemical, and biological processes by which ecosystems affect climate through various spatial and temporal scales. In the evaluation run, the ERA-Interim data were used as boundary conditions for the RCA4 model to evaluate the ability of the model to simulate observed conditions were evaluated (Gbobaniyi et al. 2014 and Klutse et al. 2016 for an evaluation of the RCA4 model over West Africa). The RCA4-downscaled GCMs are provided in Table 1.

We use the climate data from the RCA4-downscaled GCMs to develop malaria indices in three climatological
Fig. 1 Map of the study area showing the 15 member countries; 2020 population distributions (UNWPP 2019) overlaid on the normalized difference vegetation index (NDVI)

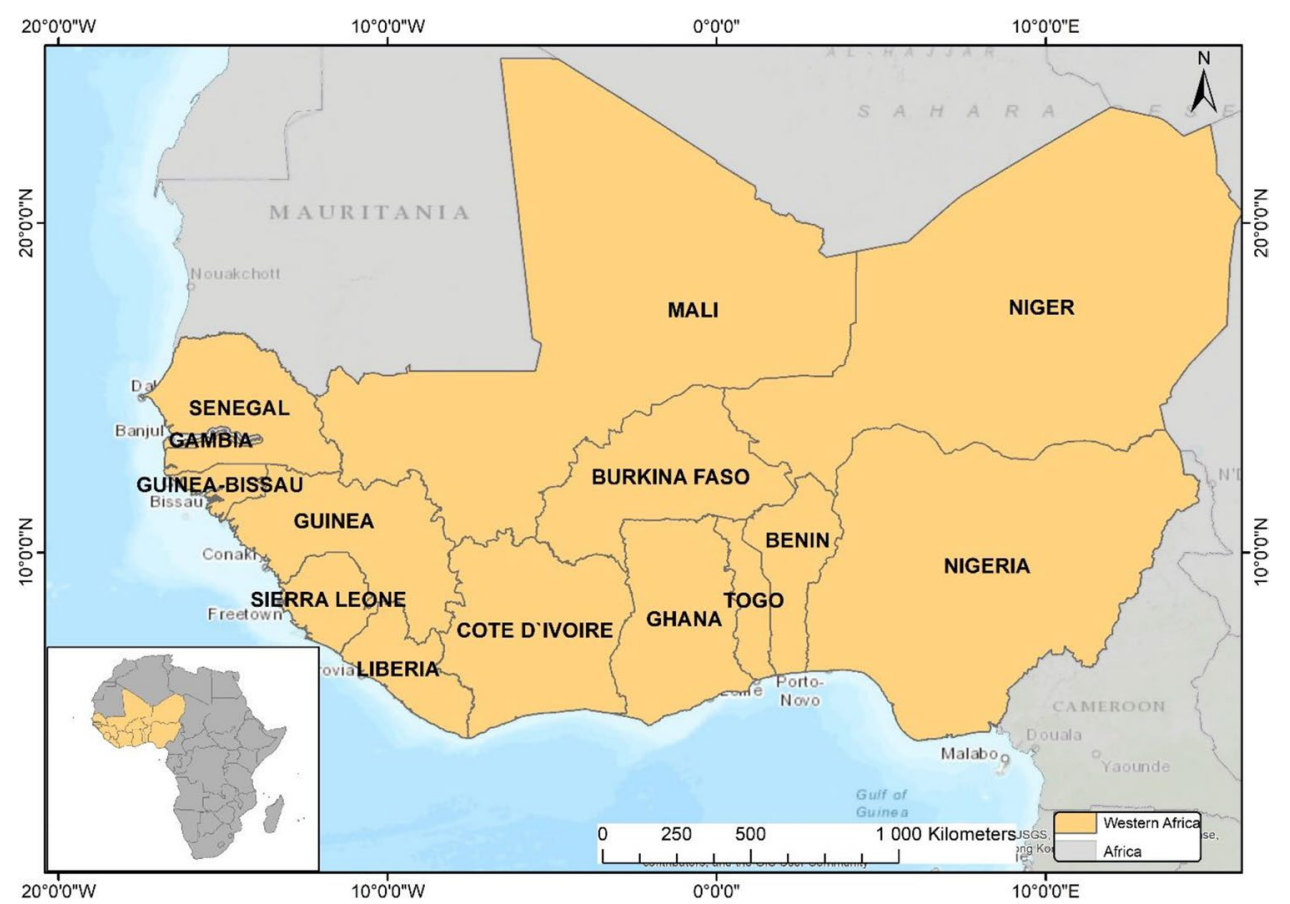


Table 1 List of the global circulation models (GCMs) used in the study

\begin{tabular}{llll}
\hline Model name & Country & Resolution & Literature \\
\hline CanESM2m & Canada & $2.8^{\circ} \times 2.8^{\circ}$ & Arora et al. (2011) \\
CNRM-CM5 & France & $1.4^{\circ} \times 1.4^{\circ}$ & Voldoire et al. (2013) \\
CSIRO-Mk3 & Australia & $1.9^{\circ} \times 1.9^{\circ}$ & Rotstayn et al. (2013) \\
IPSL-CM5A-MR & France & $1.9^{\circ} \times 3.8^{\circ}$ & Hourdin et al. (2013) \\
MIROC5 & Japan & $1.4^{\circ} \times 1.4^{\circ}$ & Watanabe et al. (2011) \\
MPI-ESM-LR & Germany & $1.9^{\circ} \times 1.9^{\circ}$ & Ilyina et al. (2013) \\
NorESMI-M & Norway & $1.9^{\circ} \times 2.5^{\circ}$ & Tjiputra et al. (2013) \\
GFDL-ESM2M & USA & $2.0^{\circ} \times 2.5^{\circ}$ & Dunne et al. (2012) \\
\hline
\end{tabular}

periods, namely historical (1980-2005), the near future (2006-2035), and the far future (2036-2065) using historical experiments and RCP4.5 and RCP8.5 scenarios. The base resolution of the domain is at $0.44^{\circ} \times 0.44^{\circ}$ for an equatorial rotated coordinate system, resulting in a quasi-regular resolution of $\sim 50 \mathrm{~km}$. The LMM takes climate data at this native resolution. The CORDEX-Africa data used in this work were obtained from the Earth System Grid Federation server (https://esgf-data.dkrz.de/projects/esgf-dkrz/). The data process was performed using a MATLAB language that includes several functions for mapping NetCDF data and organizing time series to be easily used within the box plot function.

\subsection{Liverpool malaria model (LMM)}

The LMM is a dynamical malaria model driven by daily time series of rainfall and temperature. The various components of the malaria transmission model and the parameter settings are further described by Hoshen and Morse (2004) and Ermert et al. (2011). The LMM is a mathematical-biological model of parasite dynamics, which comprises the weather-dependent within vector stages and the weatherindependent within host stages. The mosquito population is simulated using larval and adult stages, with the number of eggs deposited into breeding sites and the larval mortality rate depending on the previous 10 days' rainfall. The adult mosquito mortality rate and the egg-laying/biting cycle (socalled gonotrophic cycle) also depend on temperature.

The process of parasite transmission between humans and mosquitoes is modeled with temperature dependencies for the replication rate of the parasite within the mosquito (sporogonic cycle) and the mosquito biting rate. Both cycles evolve as a function of the number of "degree days" above a specific temperature threshold. Respectively, the gonotrophic and the sporogonic cycles take approximately 37 and 111 degree days with a threshold of $9{ }^{\circ} \mathrm{C}\left(18{ }^{\circ} \mathrm{C}\right)$ (Caminade et al. 2011). The LMM is very sensitive to the climate data inputs and the disease model parameterization. Studies about climate and health have used LMM simulations in southern Africa, including Zimbabwe and Botswana, and for the whole African continent (Morse et al. 2005, Jones and Morse 2010).

The LMM model is forced by daily rainfall and daily temperature of the RCM model, e.g., SMHI-RCA4 driven by 8 RCA4-downscaled GCMs, for the RCP4.5 and RCP8.5 emission scenarios separately.

\section{Results and discussion}

\subsection{Malaria prevalence and GCM models}

Figure 2 represents the box-and-whisker plots of the projected mean annual cycle of the malaria prevalence in West Africa for the period 2006-2100 for the RCP85 (see figure for RCP45 in supplementary material). It is an average over time and space. The RCA4-downscaled GCMs reproduce the seasonal cycle of malaria prevalence as measured against the ERA-Interim evaluation runs. They highlight a decrease in mean annual cycles and prevalence in April-June and peaks in September-November. However, the decrease is more associated with the RCA4-downscaled GCMs such as RCA4/CanESM2, RCA4/CNRM, and RCA4/IPSL than RCA4/GFDL and RCA4/NorESM1 in both scenarios.

Figure 2 shows the simulations of the different climate models in the period from 1976 to 2065, for the RCP8.5 scenario, illustrating the annual cycle of the malaria prevalence by box-whisker plots. A difference exists between the models on the amplitude of the maximum: two models have median maxima that do not even exceed $30-35 \%$ in the historical, the near future, and the far future (CanESM2 and IPSL), but all the other models have median maxima which greatly exceed this value in these different periods (around 42\%). The annual cycle is well reproduced in this scenario by all eight (8) models forcing the RCA4 regional model. The median maximum is obtained either in October (Fig. 2 a, c, and h) with the respective models CanESM2, CSIRO, and NorESM1 or in November (Fig. 2 b, d, e, $\mathrm{f}$, and g) with the CNRM, GFDL, HadGEM2, IPSL, and MIROC models for the historical period (1976-2005). For the period of the near future (2006-203) as well as the far future (2035-2065), all the models predict the peak of the prevalence in the same month as that of the historical period. Some models show the peak in October and other models in November as found in the historical period. A decrease in the peak of the prevalence of malaria is predicted by all models in the distant future. The magnitude of the decline in peak malaria prevalence for the distant future varies from model to model; for example, 
Fig. 2 Box-and-whisker plot of the projected mean annual cycle of the prevalence in West Africa. The whiskers and the maximum/minimum outliers are shown. The boxes mark the 25 th and 75 th percentile ranks, while the whiskers give the minimum and maximum values. The mean annual cycle for evaluation (black curve), historical (gray curve), near future (blue curve), and far future (red line) of the prevalence in West Africa is superposed. The position of the first quartile, third quartile, and the median is highlighted. The LMM model is forced by rainfall and temperature from the regional climate model SMHI-RCA4, respectively, driven by 8 global models: a CanESM2, b CNRM, c CSIRO, d GFDL, e HadGEM2, f IPSL, g MIROC, $\mathbf{h}$ NorESM1 for the RCP85 scenario emission
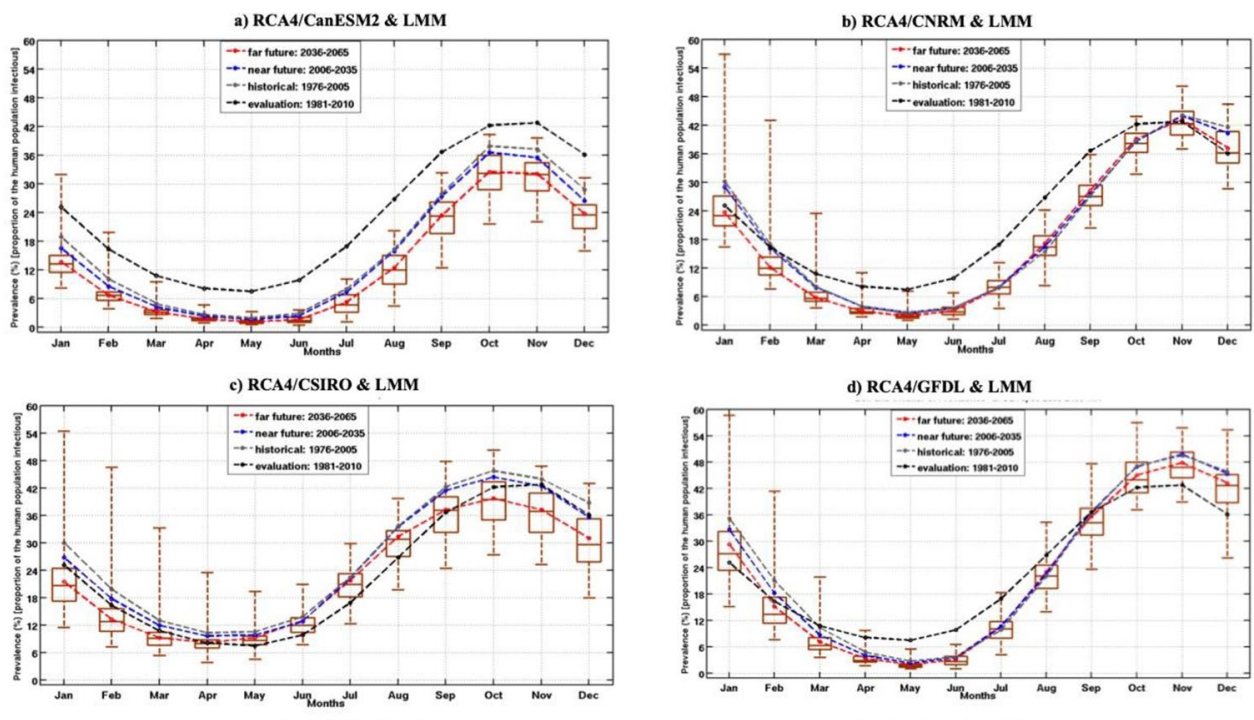

e) RCA4/HadGEM2 \& LMM
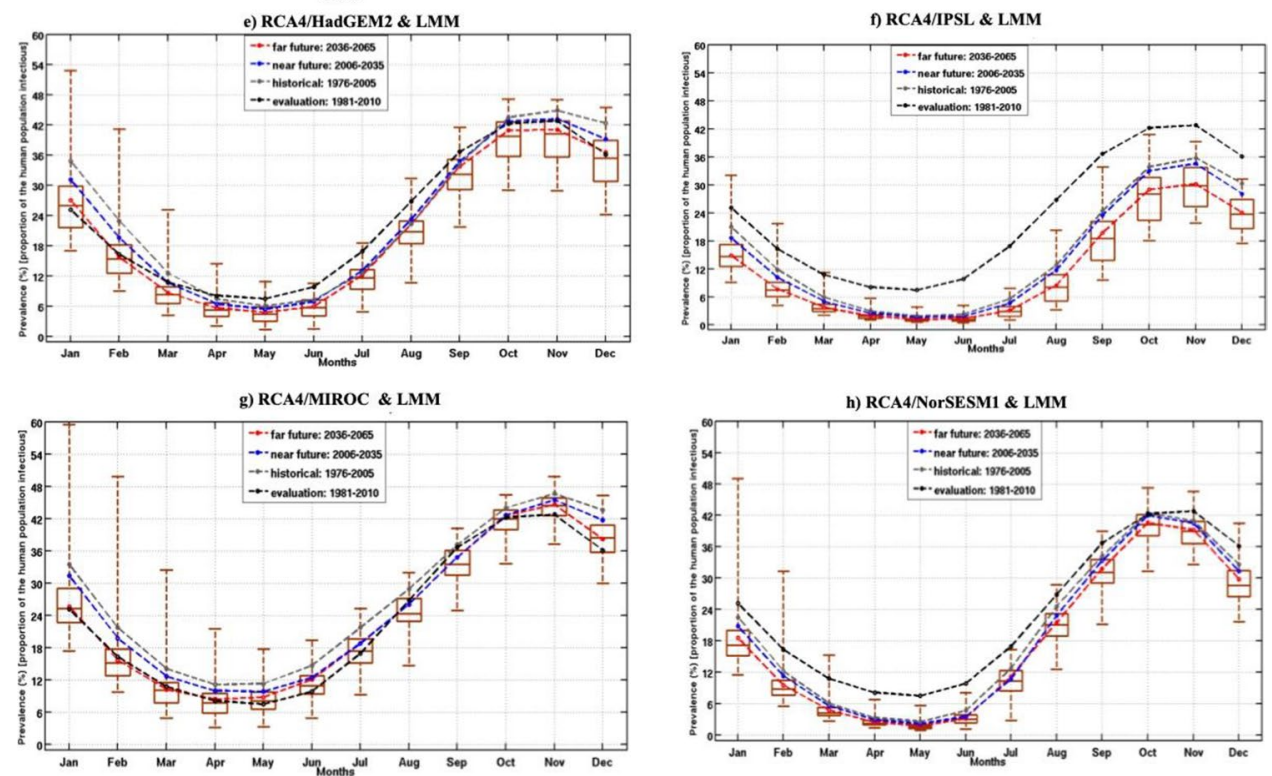

it is more marked with the models CanESM2 (Fig. 2a), CSIRO (Fig. 2c), IPSL (Fig. 2f).

The results of this study showed that the peak of malaria occurs in September-October with a lag of about 1 to 2 months from the known peak of rainfall in West Africa (July-August-September). In general, the malaria season usually occurs between September and November, with a clear peak in October. Malaria transmission takes place toward the end of the rainy season in West Africa, following both heavy and frequent monsoon rains (Diouf et al 2020). Transmission generally continues until the beginning of the dry season during unusual wet years depending on the duration of the temporary ponds. This result was consistent with previous studies using surveillance malaria data for Senegal (Diouf et al 2017). For Mali also, there were similar peaks in malaria cases from September to November (Coulibaly et al
2014) and a 3-month lag following the rainy season peak, which is also noted for Niger (Sissoko et al 2017).

These models generally underestimate the annual cycle of the malaria prevalence compared to the ERA-Interim dataset during the low malaria season and are closer to the evaluation curve in the high malaria season. However, RCA4/ CSIRO, RCA4/HadGEM2, and RCA4/MIROC show a more coherent result with ERA-Interim. Although both scenarios produced closely identical results, the decrease in malaria prevalence in the far future is more pronounced in RCP8.5 than RCP4.5. In addition, RCP8.5 provides more temporal variability as the variability appears smoother in the RCP4.5 scenario.

Figure 3 represents the Hovmöller diagram of the projected mean annual cycle for the period 2006-2099 of the prevalence in West Africa (see figure for RCP45 in supplementary material). In line with Fig. 2, the malaria prevalence 
Fig. 3 Hovmöller diagram of the projected mean annual cycle for the period 2006-2100 (2006-2099 for HadGM2) of the prevalence in West Africa: simulations of the LMM model based on the outputs of the regional climate model SMHIRCA4, respectively, driven by global models: a CanESM2, b CNRM, $\mathbf{c}$ CSIRO, $\mathbf{d}$ GFDL, $\mathbf{e}$ HadGEM2, f IPSL, g MIROC, h NorESM1 for the RCP85 scenario emission
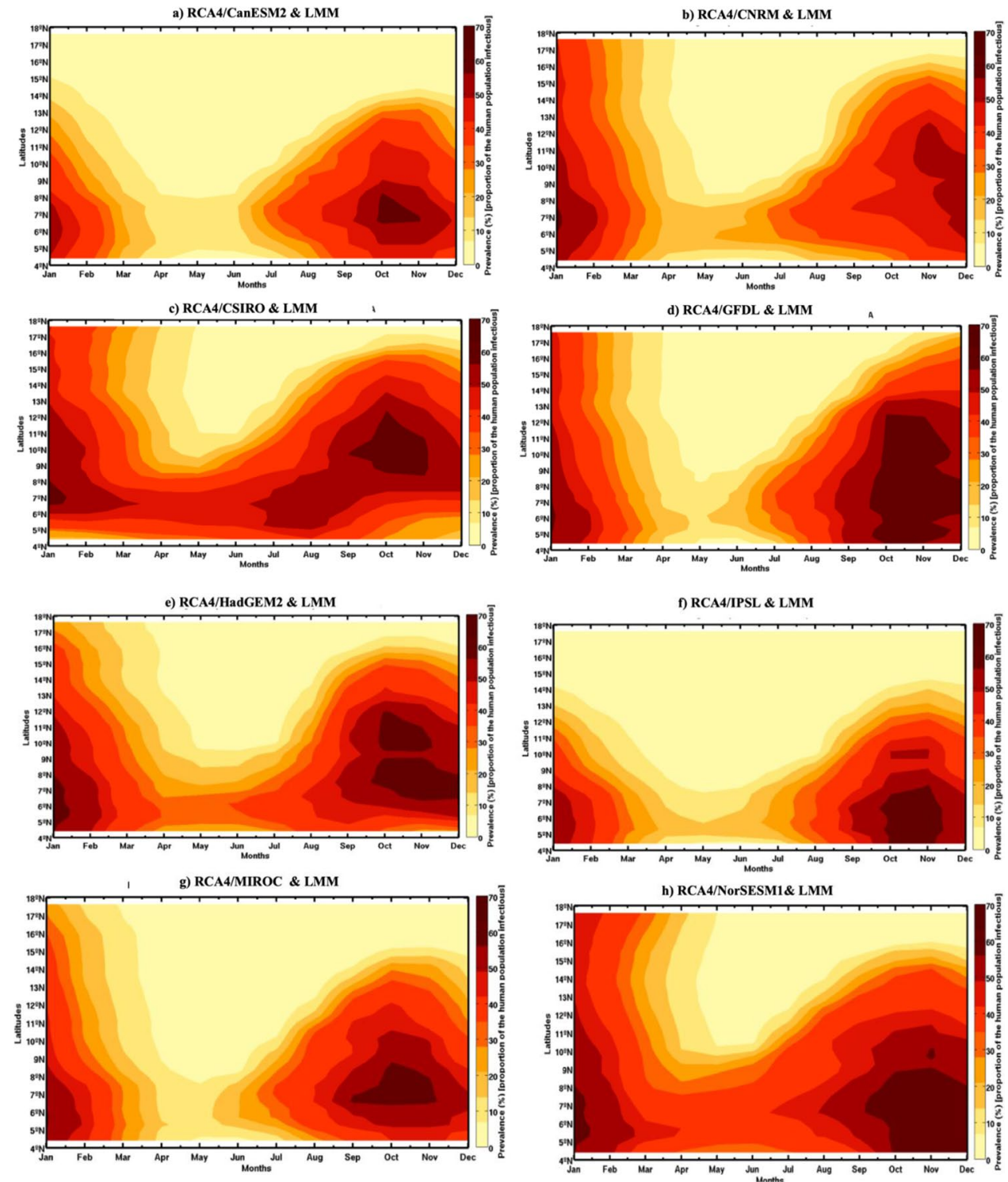

shows a maximum between September and November, while the rainfall usually peaks between July and September in West Africa (Folland et al. 1986; Sultan and Janicot 2003; Louvet 2008; Gbobaniyi et al. 2014). Regarding the spatial variability (y-axis), all the RCA4-downscaled GCMs show a latitudinal gradient with a stronger signal in the southern latitudes.

In addition, they, except RCA4/MIROC and RCA4/NorSESM1, show similar signals of prevalence in both scenarios. RCA4/MIROC shows a stronger and more extended signal in RCP4.5 than RCP8.5 and vice versa for RCA4/NorSESM1.

Figure 4 represents the intra- and interannual variability (2006-2099) of malaria prevalence in West Africa (see figure for RCP45 in supplementary material). Again, all models downscaled show similar predominant decreases in interannual variability and during the seasonal maximum malaria incidence in September-November.
However, in both RCP scenarios, RCA4/GFDL and RCA4/MIROC show the highest prevalence, while RCA4/ CanESM2 and RCA4/IPSL give the least prevalence even during periods of high malaria occurrence. Also, the prevalence signal is noticeably strong for RCA4/MIROC throughout the year and during September to November. This reinforcement results from climatic parameters specific to the RCA4/MIROC model, intrinsically based on various components such as atmosphere, earth, river, ice, and ocean (Barnett et al. 2008). Although the decrease is less visible for the RCA4/CanESM2 and RCA4/IPSL, considering the intra and interannual variability, RCP8.5 shows a clearly stronger signal for all models compared to RCP4.5.

The latitudinal gradient highlighted in Fig. 3 is better exhibited in Fig. 5 representing the averaged (along the longitude) prevalence in West Africa. 
Fig. 4 Intra- and interannual variability (2006-2099) of the prevalence in West Africa: The LMM model is forced by rainfall and temperature from the regional climate model SMHIRCA4, respectively, driven by global models: a CanESM2, b CNRM, c CSIRO, $\mathbf{d}$ GFDL, $\mathbf{e}$ HadGEM2, f IPSL, g MIROC, h NorESM1 for the RCP85 scenario emission

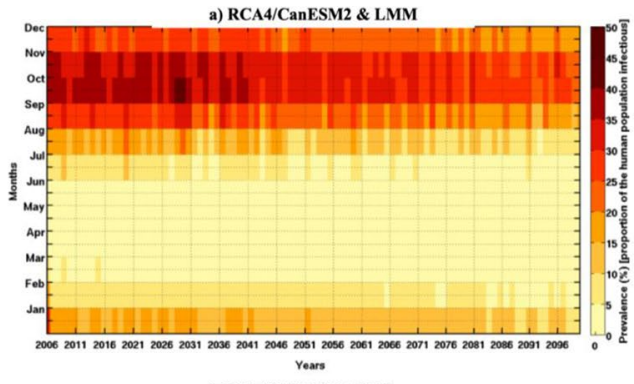

c) RCA4/CSIRO \& LMM
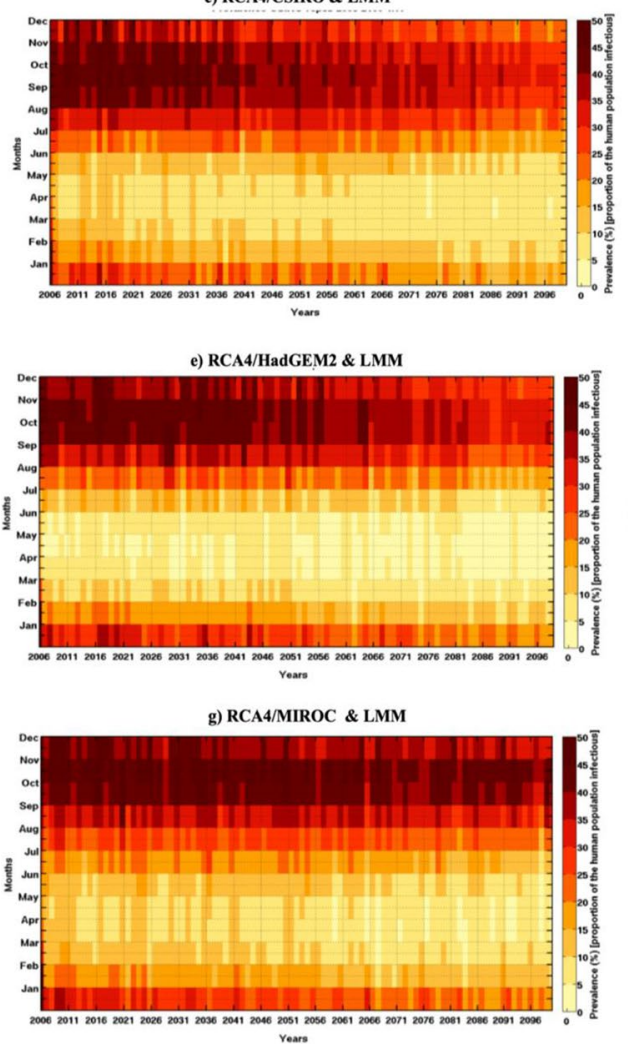

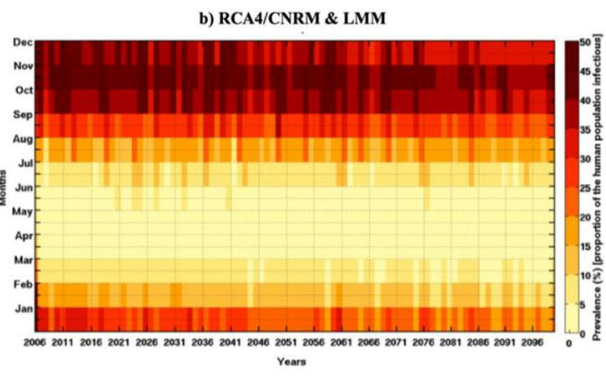

d) RCA4/GFDL \& LMM

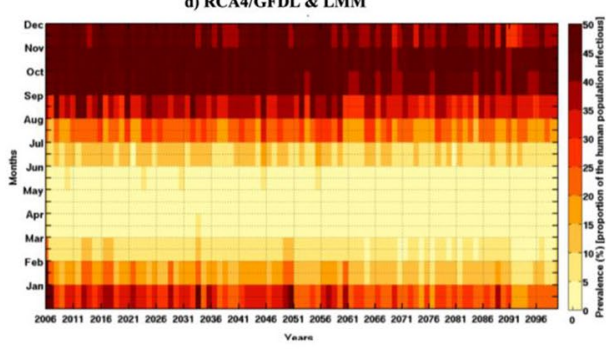

f) RCA4/IPSL \& LMM

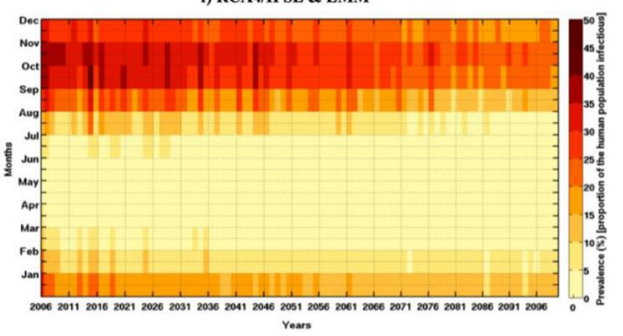

h) RCA4/NorSESM1\& LMM

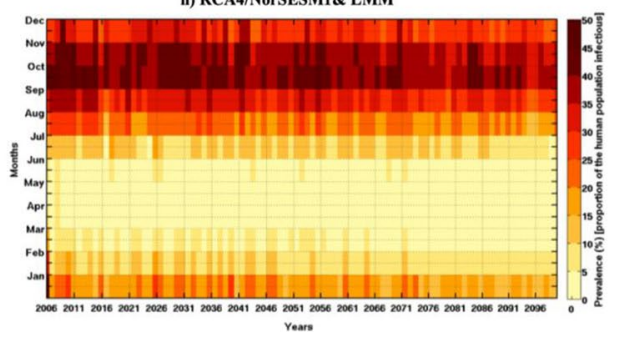

A net decrease of malaria prevalence is found from southern to northern latitudes in all the RCA4-downscaled GCMs. In addition, this Fig. 5 confirms the results in Fig. 2 on the comparison of different periods including the evaluation with ERA-Interim dataset (black curve) by distinguishing the historical period (gray curve), the near future (blue curve), and the far future (red line) for each model. In line with Fig. 2, RCA4/CanESM2, CNRM, and RCA4/IPSL, more than RCA4/GFDL and RCA4/NorESM1, underestimate prevalence compared to the ERA-Interim dataset in both scenarios. Again, RCA4/HadGEM2, RCA4/GFDL, and RCA4/MIROC produced more consistent results with observed data in RCP4.5 and RCP8.5.

Figure 6 presents the differences between the models and the evaluations runs of the malaria prevalence, respectively, for the RCP8.5 scenario (see figure for RCP45 in supplementary material) compared to the ERA-Interim dataset (evaluation).
The difference is calculated by comparing the evaluation climatological period: Prevalence for the model (1981-2010) minus evaluation for the climatological period (1980-2010). In general, the pattern of malaria prevalence change under both RCPs is one of an increase in the south of the domain, a decrease in the Sahel region and a marginal decrease to little change in the north of the domain. There are differences in spatial extent as well as in the magnitude of the change, however, the pattern is consistent in seven of the eight models except for model (RCA4/CSIRO).

\subsection{Malaria prevalence and GCM ensemble}

The simulated prevalence using ensembles of the RCA4/ GCMs for both RCP4.5 and RCP 8.5 scenarios is shown in Fig. 7 (see figure for RCP45 in supplementary material). Both scenarios indicate that malaria prevalence in the near and far future falls below evaluation and historical values. In 
Fig. 5 Averaged (along the longitude) prevalence in West Africa. The LMM model is forced by rainfall and temperature from the regional climate model SMHI-RCA4, respectively, driven by global models: a CanESM2, b CNRM, c CSIRO, d GFDL, e HadGEM2, f IPSL, $\mathbf{g}$ MIROC, $\mathbf{h}$ NorESM1 for the RCP85 scenario emission
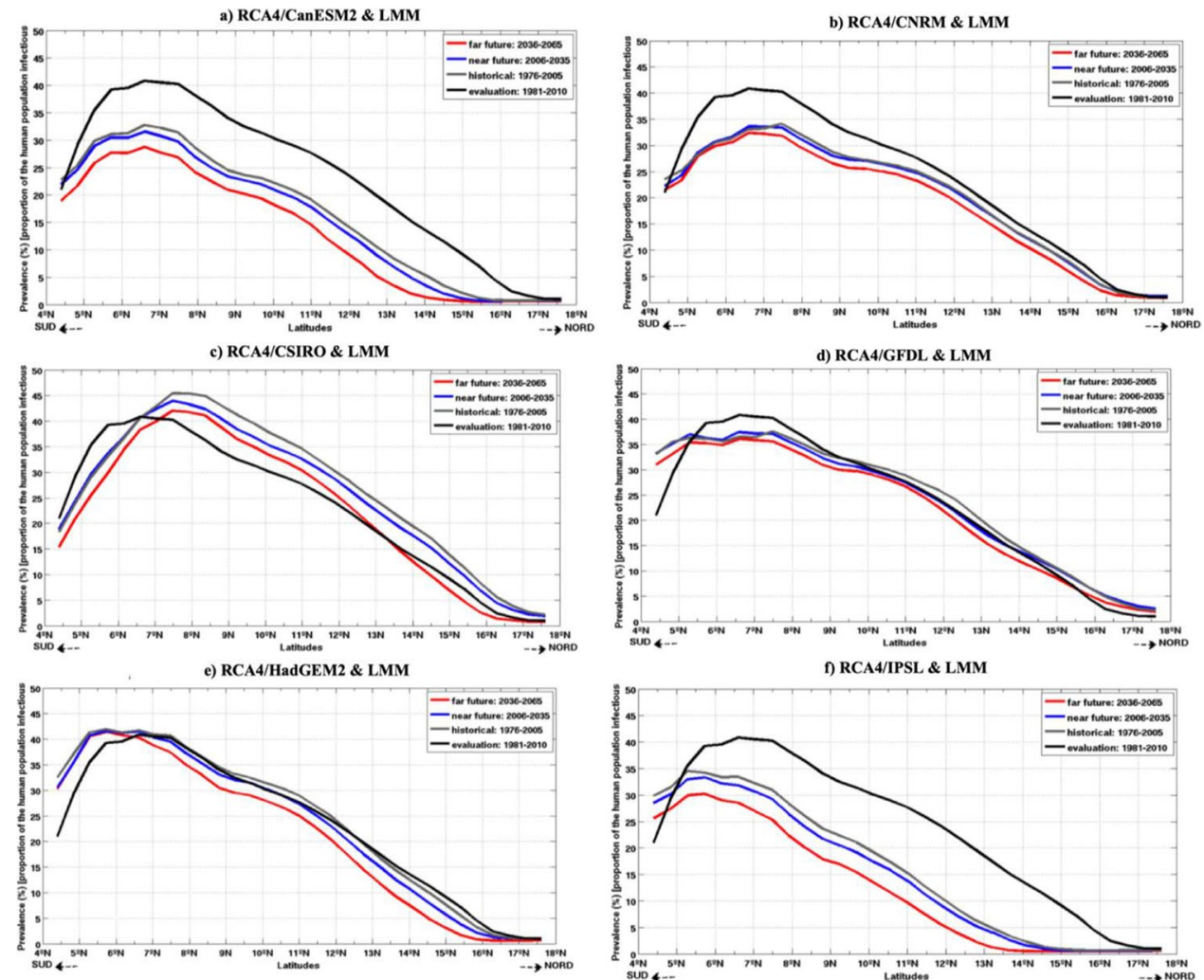

f) RCA4/IPSL \& LMM
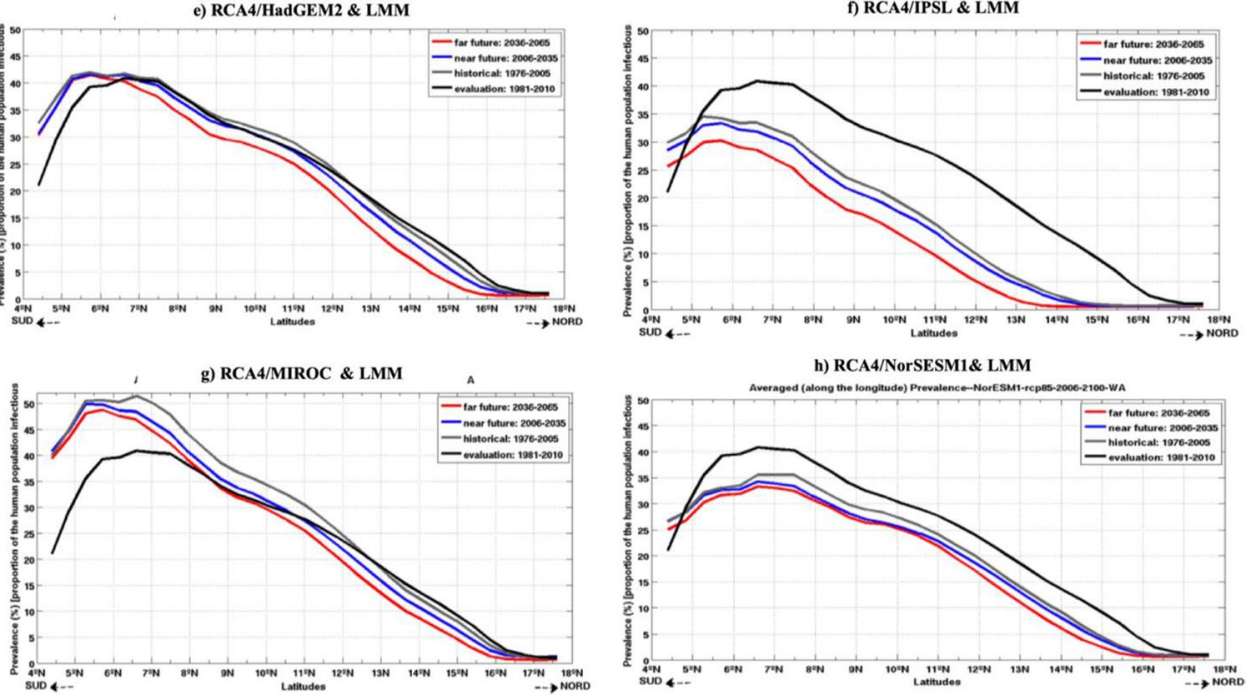

addition, September-November is identified as a transmission period with the peak between September and November, even though the intensity is more pronounced in RCP 8.5 than RCP 4.5 scenario.

However, the intensity becomes more trivial in the far future for both scenarios. For instance, in the high transmission period (September-November) for RCP 4.5 scenario (see figure for RCP45 in supplementary material), malaria prevalence falls above $40 \%$ in 2006-2057; the prevalence falls within $35-40 \%$ thereafter. Meanwhile, the intensity falls below $35 \%$ as early as 2042 for RCP 8.5 . More interestingly, the intensity is limited to the southern part of the study region with time.

The findings here suggest that malaria transmission is not expected to increase due to climate change in the far future over West Africa. The prevalence will gradually decrease with time. This is in line with other studies (Yamana and Eltahir 2013; Caminade and Jones 2016; Yamana et al. 2016). In these studies, it was concluded that malaria is expected to fall in West Africa with time. The high transmission period is consistent with the findings of Diouf et al (2017) over Senegal. In addition to these findings, our results show that malaria prevalence is expected to be shifted to the southern part of West Africa in the far future. In particular, the southern region of Cote d'Ivoire, Ghana, Togo, Benin, and Nigeria could experience more malaria intensity in future due to climate change.

\section{Conclusion}

Malaria transmission is known to be linked to seasonal rainfall with a lag of 1 to 2 months. In West Africa, while the rainfall season is at its peak in July-August-September, the peak of the malaria outbreak season occurs in September-October-November. Another important meteorological variable that influences malaria is temperature. Using the Liverpool malaria model, we have evaluated the ability 
Fig. 6 Distribution of the prevalence for the model (1980-2010) minus evaluation for the climatological period (1980-2010): The LMM model is forced by rainfall and temperature from the regional climate model SMHI-RCA4, respectively, driven by global models: a CanESM2, b CNRM, $\mathbf{c}$ CSIRO, $\mathbf{d}$ GFDL, $\mathbf{e}$ HadGEM2, f IPSL, g MIROC, h NorESM1 for the RCP85 scenario emission
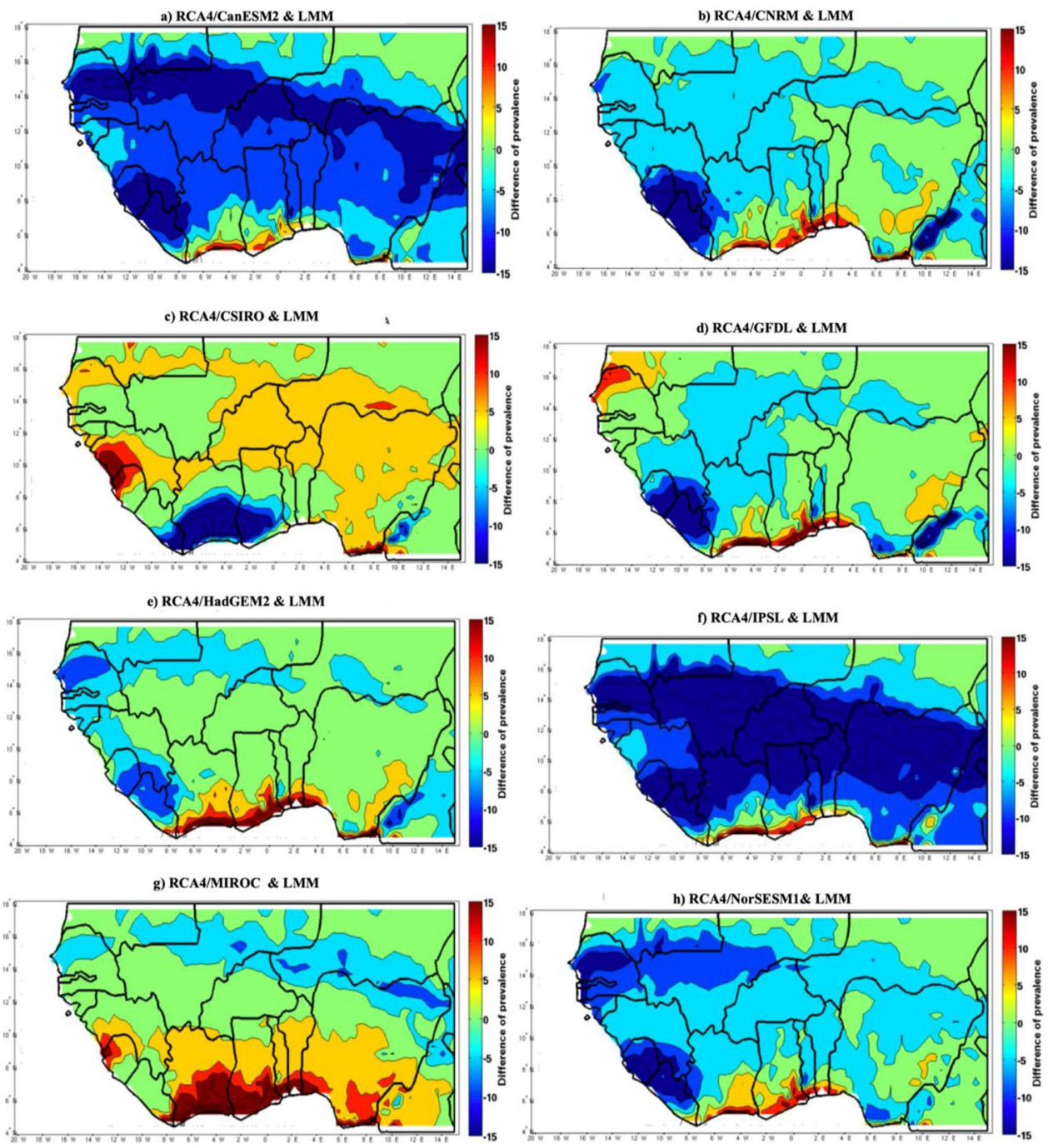

of CORDEX-driven simulations to reproduce historical malaria features over the West African domain and quantify projected changes under two RCPs, namely RCP.45 and RCP8.5. We examine each individual RCA4/GCM and LMM downscaling as well as the multi-model ensemble to improve our understanding of the timing and magnitude of regional malaria change over West Africa. Our findings show some similarities between RCP 4.5 and 8.5; however, we find malaria prevalence under RCP 8.5 is more substantial than that of RCP 4.5 especially when considering the RCA4/GCM and LMM ensemble.

In general, our results show that malaria prevalence will gradually diminish over West Africa in our near and far future periods, with the magnitude of the decrease higher in the far future. Such a decrease in malaria over the far future period seems to be associated with climate change (Gething et al. 2010; Beguin et al. 2011). However, this study highlights that malaria prevalence is expected to increase in the southern part of the study region in the future. This agrees with earlier findings in previous studies over West Africa such as Peterson (2009) who showed epidemic fringe shifted southward for most malaria models. It is expected that over the $2080 \mathrm{~s}$, climate would become so unsuitable in the northern part of the Sahel, with no more additional people at risk (Caminade et al. 2014). Beguin et al. (2011) showed an opposing effect of climate change on the global distribution of malaria, and they show a decrease in the simulated malaria behaviors over the Sahel whatever time period and scenario considered which is related to a temperature effect. So warm temperatures could impact on the adult mosquito survival scheme starting to kill a lot of adult mosquitoes in the model and that implies decrease in malaria transmission. Otherwise, the large-scale migration of populations from areas in which malaria is endemic into receptive areas will play an important role in the dynamics of the disease (WHO 1974). The health impacts of climate change will not be distributed evenly (Costello et al. 2009), and the distribution of the most severe health burdens is almost opposite to the global distribution of greenhouse gas emissions. 
Fig. 7 Same as in Figs. 1, 2, 3, 4 , and 5 computed with ensemble mean of the 8 models and for RCP85 a) Ensemble mean of RCA4/GCMs \& LMM

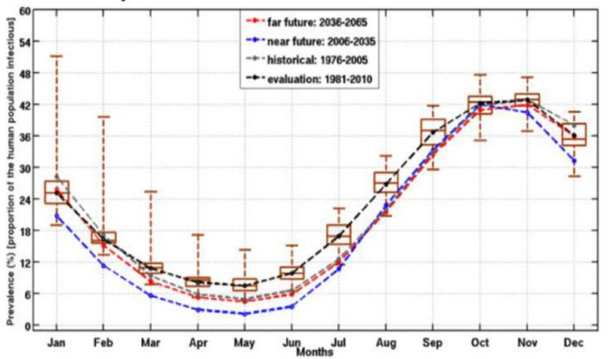

c) Ensemble mean of RCA4/GCMs \& LMM

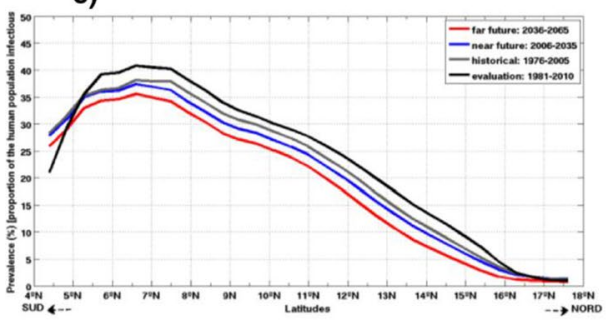

b) Ensemble mean of RCA4/GCMs \& LMM

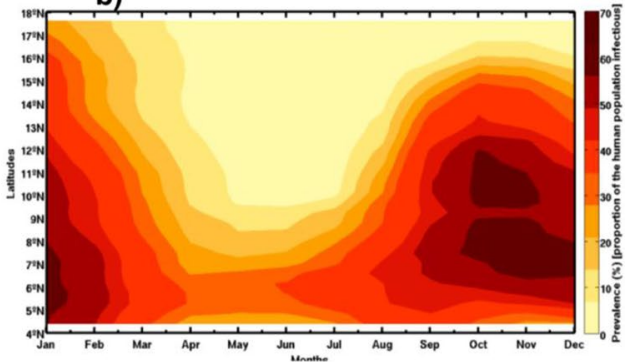

d) Ensemble mean of RCA4/GCMs \& LMM

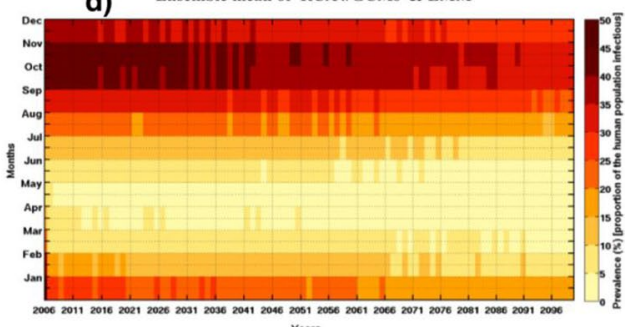

e) Ensemble mean of RCA4/GCMs \& LMM

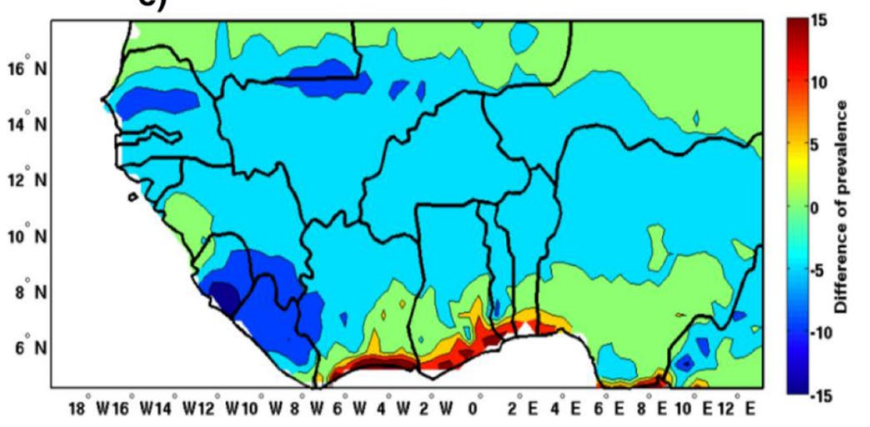

Indeed, some uncertainties driven by the RCA/GCMs but also by the impact model (LMM) might be taken into account in these findings. The change in malaria risk as simulated must be interpreted within the framework of local conditions and developments, such as the health services, the parasite reservoir, and mosquito densities. Therefore, the extent of an increase in malaria risk will be superimposed on the change in malaria transmission associated with socioeconomic development, population growth, and the effectiveness of control measures.

In the context of climate change, these results are expected to be useful for decision-makers who plan public health measures in affected countries in West Africa and elsewhere. These results can be useful for stakeholders in order to develop mitigation and vector control strategies.

The findings from this study are limited to the latest version of LMM and use climate drivers from only one RCM. In future work, we would like to use other malaria models such as VECTRI and HYDREMATS and other CORDEX downscaling to further explore the uncertainty envelope of projected malaria prevalence over West Africa and the rest of the continent.
Supplementary Information The online version contains supplementary material available at https://doi.org/10.1007/s00704-021-03807-6.

Acknowledgements The authors present their warm thanks to the downscaling centers that contributed to the CORDEX project who funded the study. The authors would like also to thank the Climate System Analysis Group who hosted the CORDEX-Africa Analysis Workshops, in the University of Cape Town, South Africa.

Author contribution Ibrahima Diouf assisted by Abiodun M. Adeola, Gbenga J. Abiodun, and Joyce Shirinde performed the experimental activities, analyzed the data, and wrote the initial manuscript. Pascal Yaka, Jacques-André Ndione, Christopher Lennard, and Emiola Gbobaniyi designed and supervised the study, performed discussion related to the CORDEX data availability and access, and improved the draft. All authors read and approved the final manuscript.

Funding This study was funded by the CORDEX project.

Availability of data and material The CORDEX-Africa data used in this work were obtained from the Earth System Grid Federation server (https://esgf-data.dkrz.de/projects/esgf-dkrz/). Data are downloaded using a wget script. 
Code availability The data process is done using a MATLAB language that includes several functions for mapping NetCDF data and organizing time.

\section{Declarations}

Ethics approval No individual person data is included in this study.

Consent to participate No persons were interviewed; all authors consent to participate in the research.

Consent for publication All authors agree to the publication of the study.

Conflict of interest The authors declare no competing interests.

Open Access This article is licensed under a Creative Commons Attribution 4.0 International License, which permits use, sharing, adaptation, distribution and reproduction in any medium or format, as long as you give appropriate credit to the original author(s) and the source, provide a link to the Creative Commons licence, and indicate if changes were made. The images or other third party material in this article are included in the article's Creative Commons licence, unless indicated otherwise in a credit line to the material. If material is not included in the article's Creative Commons licence and your intended use is not permitted by statutory regulation or exceeds the permitted use, you will need to obtain permission directly from the copyright holder. To view a copy of this licence, visit http://creativecommons.org/licenses/by/4.0/.

\section{References}

Abiodun GJ, Maharaj R, Witbooi P, Okosun KO (2016) Modelling the influence of temperature and rainfall on the population dynamics of Anopheles arabiensis. Malar J 15(1):364

Abiodun GJ, Witbooi P, Okosun KO (2017) Modeling and analyzing the impact of temperature and rainfall on mosquito population dynamics over Kwazulu-Natal, South Africa. Int J Biomath 10(04): 1750055

Abiodun GJ, Witbooi P, Okosun KO (2018) Modelling the impact of climatic variables on malaria transmission. Hacettepe Journal of Mathematics and Statistics 47(2):219-235

Alonso D, Menno MJ, Pascual M (2011) Epidemic malaria and warmer temperatures in recent decades in an East African highland. Proc. R. Soc. B

AMCEN (2011) Addressing climate change challenges in Africa; A Practical Guide Towards Sustainable Development, 255p

Armah FA, Yawson DO, Yengoh GT, Odoi JO, Afrifa EK (2010) Impact of floods on livelihoods and vulnerability of natural resource dependent communities in Northern Ghana. Water 2(2):120-139. https://doi.org/10.3390/w2020120

Arora VK, Scinocca JF, Boer GJ, Christian JR, Denman KL, Flato GM, Kharin VV, Lee WG, Merryfield WJ (2011) Carbon emission limits required to satisfy future representative concentration pathways of greenhouse gases. Geophys Res Lett 38(5):L05805. https://doi.org/10.1029/2010GL046270

Ayanlade A, Nwayor IJ, Sergi C, Ayanlade OS, Di Carlo P, Jeje OD (2020) Jegede MO (2020) Early warning climate indices for malaria and meningitis in tropical ecological zones. Sci Rep 10(1):1-3
Barnett TP, Pierce DW, Hidalgo HG, Bonfils C, Santer BD, Das T, Dettinger MD (2008) Human-induced changes in the hydrology of the western United States. Science 319(5866):1080-1083

Béguin A, Hales S, Rocklö J, Åström C, Louis VR, Sauerborn R (2011) The opposing effects of climate change and socio-economic development on the global distribution of malaria. Glob Environ Chang 21:1209-1214

Besancenot JP, Ndione JA, Handschumacher P, Ibrahima M, Laaidi K (2004) Climat, eau et santé au Sahel ouest-Africain. Science Changements Planétaires/sécheresse 15:233-241 ((In French))

Caminade C, Jones AE (2016) Epidemiology: malaria in a warmer West Africa. Nat Clim Chang 6(11):984

Caminade C, Kovats S, Rocklov J, Tompkins AM, Morse AP, ColónGonzález FJ, Lloyd SJ (2014) Impact of climate change on global malaria distribution. Proc Natl Acad Sci 111(9):3286-3291

Caminade C, Ndione JA, Kebe CMF, Jones AE, Danuor S, Tay S, Jeanne I (2011) Mapping Rift Valley fever and malaria risk over West Africa using climatic indicators. Atmospheric Science Letters 12(1):96-103

Costello A, Abbas M, Allen A, Ball S, Bell S, Bellamy R, Friel S, Groce N, Johnson A, Kett M, Lee M, Levy C, Maslin M, McCoy D, McGuire B, Montgomery H, Napier D, Pagel C, Patel J, de Oliveira JA, Redclift N, Rees H, Rogger D, Scott J, Stephenson J, Twigg J, Wolff J, Patterson C (2009) Managing the health effects of climate change: Lancet and University College London Institute for Global Health Commission. Lancet 373:1693733

Coulibaly D, Travassos MA, Kone AK, Tolo Y, Laurens MB, Traore K, Sissoko M (2014) Stable malaria incidence despite scaling up control strategies in a malaria vaccine-testing site in Mali. Malar J 13:374

Dee DP, Uppala SM, Simmons AJ, Berrisford P, Poli P, Kobayashi S, Andrae U, Balmaseda MA, Balsamo G, Bauer DP, Bechtold $P$ (2011) The ERA-Interim reanalysis: configuration and performance of the data assimilation system. Q J R Meteorol Soc 137(656):553-597

Dieterich C, Schimanke S, Wang S, Väli G, Liu Y, Hordoir R, Axell L, Höglund A, Meier HEM (2013) Evaluation of the SMHI coupled atmosphere-ice-ocean model RCA4_NEMO; SMHI- Report, RO 47, ISSN 0283-1112

Diouf I, Deme A, Ndione JA, Gaye AT, Rodríguez-Fonseca B, Cisse M (2013) Climate and health: observation and modeling of malaria in the Ferlo (Senegal). CR Biol 336(5-6):253-260. https://doi.org/ 10.1016/j.crvi.2013.04.001

Diouf I, Fonseca BR., Caminade C, Thiaw WM, Deme A, Morse AP., ... \& Ngom Ndiaye, MK. (2020) Climate variability and malaria over West Africa. The American Journal of Tropical Medicine and Hygiene, tpmd 190062

Diouf I, Rodríguez-Fonseca B, Deme A, Caminade C, Morse AP, Cisse M, Sy I, Dia I, Ermert V, Ndione JA, Gaye AG (2017) Comparison of malaria simulations driven by meteorological observations and reanalysis products in Senegal. Int J Environ Res Public Health 14(10):1119. https://doi.org/10.3390/ijerph14101119

Dunne JP, John JG, Adcroft AJ, Griffies SM, Hallberg RW, Shevliakova E, Stouffer RJ, Cooke W, Dunne KA, Harrison MJ, Krasting JP, Malyshev SL, Milly PCD, Phillipps PJ, Sentman LT, Samuels BL, Spelman MJ, Winton M, Wittenbarg AT, Zadeh N (2012) GFDL's ESM2 global coupled climate-carbon earth system models Part I: Physical Formulation and Baseline Simulation Characteristics. J Clim 25(19):6646-6665

Ermert V, Fink AH, Jones AE, Morse AP (2011) Development of a new version of the Liverpool malaria model I. Refining the parameter settings and mathematical formulation of basic processes based on a literature review. Malar J 10:35

Folland CK, Palmer TN, Parker DE (1986) Sahel rainfall and worldwide sea temperatures, 1901-85. Nature 320(6063):602-607 
Freeman T, Bradley M (1996) Temperature is predictive of severe malaria years in Zimbabwe. Trans R Soc Trop Med Hyg 90:232

Gadiaga L, Machault V, Pagès F, Gaye A, Jarjaval F, Godefroy L, Rogier C (2011) Conditions of malaria transmission in Dakar from 2007 to 2010. Malar J 10(1):312

Gagnon AS, Smoyer-Tomic KE, Bush AB (2002) The El Nino southern oscillation and malaria epidemics in South America. Int J Biometeorol 46(2):81-89

Gbobaniyi E, Sarr A, Sylla MB, Diallo I, Lennard C, Dosio A, Dhiédiou A, Kamga A, Klutse NAB, Hewitson B, Nikulin G (2014) Climatology, annual cycle and interannual variability of precipitation and temperature in CORDEX simulations over West Africa. Int J Climatol 34(7):2241-2257

Gething PW, Smith DL, Patil AP, Tatem AJ, Snow RW, Hay SI (2010) Climate change and the global malaria recession. Nature 465(7296):342

Githeko AK, Ndegwa (2001) Predicting malaria epidemics in the Kenyan highlands using climate data: a tool for decision makers. Global change and human health 2(1):54-63

Gupta S, Hill AS (1998) Dynamic interaction in malaria: host heterogeneity meets parasite polymorphism. Proc Soc Lond B 261:361-370

Hanf M, Adenis A, Nacher M, Carme B (2011) The role of El Niño southern oscillation (ENSO) on variations of monthly Plasmodium falciparum malaria cases at the cayenne general hospital, 1996-2009. French Guiana Malaria Journal 10(1):1-4

Hoshen MB, Morse AP (2004) A weather-driven model of malaria transmission. Malar J 3:32

Hourdin, F., Foujols, M. A., Codron, F., Guemas, V., Dufresne, J. L., Bony, S., Denvil, Sebastien, Guez, L., Lott, F., Ghattas, J., Braconnot, P., Marti, O., Meurdesoif, Y. and Bopp, L. (2013) Impact of the LMDZ atmospheric grid configuration on the climate and sensitivity of the IPSL-CM5A coupled model. Clim. Dyn., 40, https://doi.org/10.1007/s00382-012-1411-3, 2167-2192.

Hulme M (1992) Rainfall changes in Africa: 1931-1960 to 1961-1990 Int. J Climatol 12:685-699

Ilyina T, Six KD, Segschneider J, Maier-Reimer E, Li H, Nuńez-Riboni I (2013) The global ocean biogeochemistry model HAMOCC: model architecture and performance as component of the MPIEarth System Model in different CMIP5 experimental realizations. J Adv Model Earth Syst. 10.002/jame.20017

Jones A, Morse A (2010) Application and validation of a seasonal ensemble prediction system using a dynamic malaria model. J. Clim 23:4202-4215

Jones C, Giorgi F, Asrar G (2011a) The coordinated regional downscaling experiment: CORDEX an international downscaling link to CMIP5. CLIVAR Exchanges 16:34-40

Jones CG, Samuelsson P, Kjellstrom E (2011b) Regional climate modelling at the Rossby Centre. Tellus a: Dynamic Meteorology and Oceanography 63(1):1-3

Klutse NAB, Ajayi V, Gbobaniyi EO, Egbebiyi TS, Kouadio K, Nkrumah F, \& Lawal KAA (2018) Potential impact of $1.5^{\circ} \mathrm{C}$ and $2^{\circ}$ $\mathrm{C}$ global warming on consecutive dry and wet days over West Africa. Environmental Research Letters

Klutse NAB, Sylla MB, Diallo I, Sarr A, Dosio A, Diedhiou A, Kamga A, Lamptey B, Ali A, Gbobaniyi EO, Owusu K (2016) Daily characteristics of West African summer monsoon precipitation in CORDEX simulations. Theoret Appl Climatol 123(1-2):369-386

Kovats RS, Bouma MJ, Hajat S, Worrall E, Haines A (2003) El Nino and Health Lancet 362:1481-1489

Kreppel K, Caminade C, Govella N, Morse AP, Ferguson HM, Baylis M (2019) Impact of ENSO 201-17 on regional climate and malaria vector dynamics in Tanzania. Environmental Research Letters 14(7):075009

Lindsay SW, Birley MH (1996) Climate change and malaria transmission Ann. Trop Med Parasitol 6:5
Louvet S (2008) Modulations intrasaisonnières de la mousson d'Afrique de l'Ouest et impacts sur les vecteurs du paludisme à Ndiop (Sénégal): diagnostics et prévisibilité. Doctoral dissertation, Université de Bourgogne

Mabaso ML, Kleinschmidt I, Sharp B, Smith T (2007) El Niño southern oscillation (ENSO) and annual malaria incidence in southern Africa. Trans R Soc Trop Med Hyg 101(4):326-330

Magadza CHD (2000) Climate change impacts and human settlements in Africa: prospects for adaptation. Environ Monit Assess 61(1):193-205

Makinde OS, Abiodun GJ, Ojo OT (2021) Modelling of malaria incidence in Akure, Nigeria: negative binomial approach. GeoJournal 86(3):1327-1336

Menne B, R Bertollini (2000) The health impacts of desertification and drought. In: Down to earth. The Newsletter of the Convention to Combat Desertification. 14: 4-6

Morse AP, Doblas-Reyes FJ, Hoshen MB, Hagedorn R, Palmer TNA (2005) Forecast quality assessment of an end-to-end probabilistic multi-model seasonal forecast system using a malaria model. Tellus 57:464-475

Mouchet J, Faye O, Julvez J, Manguin S (1996) Drought and malaria retreat in the Sahel, West Africa. Lancet 348:1735-1736

Newby G, Hwang J, Koita K, Chen I, Greenwood B, von Seidlein L, Shanks GD, Slutsker L, Kachur SP, Wegbreit J (2015) Review of mass drug administration for malaria and its operational challenges. Am J Trop Med Hyg 93:125-134

Nka BN, Oudin L, Karambiri H, Paturel JE, Ribstein P (2015) Trends in floods in West Africa: analysis based on 11 catchments in the region. Hydrol Earth Syst Sci 19(11):4707-4719

Pascual M, Jorge A, Ahumada LF, Xavier R, Menno B (2006) Malaria resurgence in the East African highlands: temperature trends revisited. Proc Natl Acad Sci 103(15):5829-5834

Peterson AT (2009) Shifting suitability for malaria vectors across Africa with warming climates. BMC Infect Dis 9:59

Poveda G, Rojas W, Quinones ML, Velez ID, Mantilla RI, Ruiz D, Zuluaga JS, Rua GL (2001) Coupling between annual and ENSO timescales in the malaria climate association in Colombia. Environ Health Perspect 109:489-493

Rotstayn LD, Collier MA, Jeffrey SJ, Kidston J, Syktus JI, Wong KK (2013) Anthropogenic effects on the subtropical jet in the Southern Hemisphere: aerosols versus long-lived greenhouse gases. Environ Res Lett 8 https://doi.org/10.1088/17489326/8/1/014030.

Sissoko MS, Sissoko K, Kamate B, Samake Y, Goita S, Dabo A, Gaudart J (2017) Temporal dynamic of malaria in a suburban area along the Niger River. Malar J 16:420

Sultan B, Janicot S (2003) The West African monsoon dynamics. Part II: The "preonset" and "onset" of the summer monsoon. J Climate 16:3407-3427

Tjiputra JF, Roelandt C, Bentsen M, Lawrence DM, Lorentzen T, Schwinger J, Seland $\varnothing$, Heinze C (2013) Evaluation of the carbon cycle components in the Norwegian earth system model (NorESM). Geosci Model Dev 6, 10.5194/gmd-6-301-2013, 301-325

Tompkins AM, Ermert V (2013) A regional-scale, high resolution dynamical malaria model that accounts for population density, climate and surface hydrology. Malar J 12(1):65

Tourre YM, Vignolles C, Viel C, Mounier F (2017) Climate impact on malaria in northern Burkina Faso. Geospatial health, 12(2)

UNEP 2013 Africa Environment Outlook 3: Our Environment, Our Health. Africa Environment Outlook, 242p

UNWPP: World Population Prospects (2019 Revision) - United Nations population estimates and projections.

Voldoire A, Sanchez-Gomez E, Salas y Mélia D, Decharme B, Cassou C, Sénési S, Valcke S, Beau I, Alias A, Chevallier M, Déqué M, Deshayes J, Douville H, Fernandez E, Madec G, Maisonnave E, Moine MP, Planton S, Saint-Martin D, Szopa S, Tyteca S, 
Alkama R, Belamari S, Braun A, Coquart L, Chauvin F (2013) The CNRM-CM5.1 global climate model: description and basic evaluation. Climate Dyn. 40:2091-2121. https://doi.org/10.1007/ s00382-011-1259-y

Wandiga SO, Opondo M, Olago D, Githeko A, Githui F, Marshall M, Yanda PZ (2010) Vulnerability to epidemic malaria in the highlands of Lake Victoria basin: the role of climate change/ variability, hydrology and socio-economic factors. Clim Change 99(3-4):473-497

Watanabe S, Hajima T, Sudo K, Nagashima T, Takemura T, Okajima H, Nozawa T, Kawase H, Abe M, Yokohata T, Ise T, Sato H, Kato E, Takata K, Emori S, Kawamiya M (2011) MIROC-ESM 2010: model description and basic results of CMIP5-20c3m experiments. Geosci Model Dev 4: 10.5194/gmd-4-845-2011,845-872

WHO (1974) Malaria control in countries where time-limited eradication is impracticable at present. Report of a WHO Interregional conference, Geneva
WHO (2020) World malaria report: 20 years of global progress and challenges. Geneva.

Yamana TK, Bomblies A, Eltahir EA (2016) Climate change unlikely to increase malaria burden in West Africa. Nat Clim Chang 6(11):1009

Yamana TK (2013) Eltahir EA Projected impacts of climate change on environmental suitability for malaria transmission in West Africa (2013). Environmental health perspectives. 121(10):1179

Publisher's note Springer Nature remains neutral with regard to jurisdictional claims in published maps and institutional affiliations. 